\title{
AVALIAÇÃO DA CAPACIDADE FERMENTATIVA E DO CRESCIMENTO CELULAR DA LEVEDURA Saccharomyces cerevisiae CCT-3174
}

\author{
S. ORTIZ ${ }^{1}$, E. L. SIMIONATTO ${ }^{2}$ e A. A. C. BARROS ${ }^{3}$ \\ ${ }^{1}$ Universidade Federal de Santa Catarina, Departamento de Engenharia Química e Engenharia de \\ Alimentos \\ ${ }^{2}$ Universidade Regional de Blumenau, Departamento de Química \\ ${ }^{3}$ Instituto Superior Politécnico de Tecnologias e Ciências, Departamento de Engenharias e \\ Tecnologias, Luanda, Angola \\ E-mail para contato: samaraeq@gmail.com
}

\begin{abstract}
RESUMO - Em relação ao bioetanol, pesquisa-se principalmente sua obtenção a partir de resíduos agroindustriais. Porém, a levedura utilizada na fermentação alcoólica também influencia na produtividade. Neste contexto, este trabalho visa estudar a capacidade fermentativa e o crescimento celular da levedura Saccharomyces cerevisiae CCT-3174. A fermentação alcoólica foi realizada em $300 \mathrm{ml}$ de meio composto por D-glucose $(10 \mathrm{~g} / \mathrm{l})$, peptona bacteriológica $(5 \mathrm{~g} / \mathrm{l})$, extrato de levedura ( $3 \mathrm{~g} / \mathrm{l})$ e extrato de malte $(3 \mathrm{~g} / \mathrm{l})$, dissolvidos em água destilada e esterilizados por 15 minutos a $121^{\circ} \mathrm{C}$. Esta etapa do experimento foi conduzida por 30 horas em agitador orbital com agitação de $120 \mathrm{rpm}$ e temperatura de $30^{\circ} \mathrm{C}$. Coletaram-se amostras a cada duas horas para análise de dados cinéticos. O rendimento da reação foi superior a 90\%, o que comprova sua potencialidade para fermentação alcoólica. Sendo assim, esta linhagem é propícia para estudos futuros de obtenção de bioetanol.
\end{abstract}

\section{INTRODUÇÃO}

Existem dois métodos de obtenção de etanol, por via sintética ou via fermentativa (Borzani et al., 2001). A via de obtenção de etanol mais utilizada no Brasil é a fermentativa por questões econômicas, domínio de tecnologia e disponibilidade de biomassa (Vieira et al., 2009).

De acordo com Borzani et al. (2001), todos os substratos açucarados são passíveis de fermentação, sendo estes açúcares convertidos em etanol e dióxido de carbono, por processo anaeróbio. Esta transformação envolve uma sequência de 12 reações catalisadas por enzimas. A fermentação alcoólica ocorre no citoplasma da célula, onde se localizam estas enzimas, denominadas de enzimas glicolíticas. A fermentação pode ser realizada a partir de açúcares, amido ou celulose. O desempenho do processo fermentativo depende diretamente das enzimas glicolíticas, pois estas podem ser estimuladas ou inibidas por diversos fatores, como por exemplo, $\mathrm{pH}$, nutrientes, entre outros. 


\section{9 a 22 de outubro de 2014 \\ Florianópolis/SC}

As leveduras são os microrganismos mais utilizados na fermentação alcoólica. A levedura atualmente utilizada em escala comercial é a Saccharomyces cerevisiae, que é um aeróbio facultativo. Porém, as bactérias também são capazes de produzir etanol, mas, por questões econômicas (rendimento em produto), não são utilizadas. Para a fermentação alcoólica é adicionada à mistura uma população de leveduras responsáveis por metabolizar os carboidratos, transformando estes em etanol e liberando dióxido de carbono. Esta etapa pode ocorrer em processo contínuo ou batelada (Hahn-Hagerdal, 2006).

Existem diversos fatores que afetam a fermentação alcoólica como um todo. Dentre eles pode-se citar a levedura utilizada. Leveduras de culturas puras fornecidas por instituições do ramo se comportam de forma diferente que a levedura comercial, utilizada para fabricação do pão (Borzani et al., 2001).

As leveduras necessitam de fonte de carbono que forneça energia, sendo esta fonte a glicose ou outro açúcar. O meio deve ser fonte de algumas vitaminas, nitrogênio, ferro, cobre, enxofre, fósforo, entre outros. A levedura Saccharomyces cerevisiae praticamente não é capaz de se beneficiar com as proteínas do meio e também não possui capacidade metabólica de aproveitar o nitrogênio em forma de nitrato, somente na forma amoniacal, amídica ou amínica. As leveduras são microrganismos mesófilos, sendo que a temperatura ótima está entre $26-35^{\circ} \mathrm{C}$. O controle de temperatura é essencial, pois caso a temperatura aumente, a velocidade da fermentação consequentemente aumenta, elevando o risco de contaminação e tornando a levedura mais sensível à toxidade do etanol gerado (Borzani et al., 2001).

Dodic et al. (2009) estudaram a fermentação alcoólica utilizando polpa de beterraba diluída em água destilada como meio de cultivo, visando a obtenção de bioetanol. Após 72 horas de cultivo, o melhor rendimento obtido foi de 12\%. Mohanty et al. (2009) também estudaram a fermentação alcoólica utilizando a levedura Saccharomyces cerevisiae comercial. O meio de cultivo utilizado pelos autores foi flores de mahula.

Vieira et al. (2009) obtiveram em seu estudo, bioetanol a partir do mesocarpo do babaçu, que é rico em amido na sua composição. Primeiramente, foi realizada a hidrólise enzimática do amido. Para a etapa da fermentação alcoólica, a levedura utilizada foi uma linhagem comercial da Saccharomyces cerevisiae. O rendimento obtido foi de $350 \mathrm{~mL}$ de etanol por quilograma de amido. Xiros et al. (2008) estudaram a fermentação de resíduos de cervejarias, sendo constituídos basicamente de cascas de cereais. A hidrólise aplicada aos resíduos foi a alcalina. O microrganismo utilizado na fermentação alcoólica foi o fungo Neurospora crassa DSM 1129. Os autores obtiveram neste experimento rendimento de 74 gramas de etanol por quilograma de resíduo seco.

Ortiz (2010) estudou a produção de bioetanol, a partir de bagaço de malte e bagaço de mandioca, utilizando a levedura Saccharomyces cerevisiae CCT-0294 e da linhagem comercial, para fins comparativos. A hidrólise enzimática dos resíduos foi conduzida através de fermentação em estado sólido pelo fungo Rhizopus oryzae ATCC 34612. Para as condições de estudo, a levedura da linhagem CCT-0294 mostrou-se mais viável na fermentação alcoólica, apresentado 
rendimento de $46,58 \%$, enquanto que o rendimento máximo obtido nas fermentações com a levedura comercial foi de $39,73 \%$.

Percebe-se que pesquisas na área de bioetanol possibilitam novos estudos em diversos aspectos, como a utilização de resíduos de diferentes processos, assim como a utilização de diferentes espécies microbianas na fermentação alcoólica.

\subsection{Objetivo}

Este trabalho tem por objetivo estudar a capacidade fermentativa e o crescimento celular da levedura Saccharomyces cerevisiae CCT-3174, através da análise da concentração biomassa, do consumo do substrato (glicose) e da análise de parâmetros cinéticos.

\section{METODOLOGIA}

\subsection{Fermentação Alcoólica}

Para esta etapa, preparou-se $300 \mathrm{ml}$ de meio, composto por $10 \mathrm{~g} / \mathrm{l} \mathrm{de} \mathrm{D-glucose,} 5 \mathrm{~g} / \mathrm{l} \mathrm{de}$ peptona bacteriológica, $3 \mathrm{~g} / \mathrm{l}$ de extrato de levedura e $3 \mathrm{~g} / \mathrm{l}$ de extrato de malte. Os componentes foram dissolvidos em água destilada e o meio foi esterilizado em autoclave à temperatura de $121^{\circ} \mathrm{C}$, por 15 minutos (Ortiz, 2010).

A inoculação foi realizada na câmara de fluxo laminar, a partir da cepa crescida em placa de Petri, que foi adicionada ao meio na quantidade de duas alçadas de célula. $\mathrm{O}$ cultivo foi realizado em incubadora de movimento orbital Tecnal modelo TE-420, a $30^{\circ} \mathrm{C}$ e com velocidade de agitação de $120 \mathrm{rpm}$. O cultivo foi acompanhado por 30 horas, com retirada de amostra a cada 2 horas, para aquisição de dados cinéticos. Todas as amostras foram analisadas no final do experimento. O produto da reação (etanol) foi quantificado apenas no final da fermentação alcoólica. $\mathrm{O}$ experimento foi realizado em duplicata.

\subsection{Procedimentos Analíticos}

Crescimento Celular: Inicialmente, foi graficada a reta de calibração da concentração celular versus a absorbância lida no espectrofotômetro. A partir desta reta, faz-se a leitura das amostras cuja concentração celular é desconhecida, e com a absorbância obtida, quantifica-se a concentração. Para a determinação dos pontos da reta de calibração, pesou-se 0,1 grama de célula coletada da placa de Petri com uso de alça de platina esterilizada em chama, e diluiu-se em $100 \mathrm{ml}$ de água destilada, tendo assim, uma suspensão celular de concentração $1 \mathrm{~g} / \mathrm{l}$. A partir desta suspensão, foram feitas diluições, para se obter diferentes concentrações. As amostras foram lidas em espectrofotômetro Shimadzu UV-1650PC em $660 \mathrm{~nm}$.

Concentração de Glicose: A análise da concentração de glicose foi realizada pelo método da glicose oxidase. A absorbância foi medida em espectrofotômetro Shimadzu UV-1650PC em $500 \mathrm{~nm}$, e é diretamente proporcional à concentração de glicose na amostra, sendo o resultado 
expresso em $\mathrm{g} / \mathrm{l}$.

Concentração de Etanol: Após a fermentação alcoólica, o meio foi centrifugado por 15 minutos com velocidade de agitação de $7500 \mathrm{rpm}$ na centrífuga Hermle modelo Z300K. O etanol foi analisado em cromatógrafo gasoso Varian CP-3800 com detector de ionização em chama (CG-DIC) e com coluna capilar Chrompack de sílica fundida (CP-SIL PONA CB, 0,025 mm de diâmetro interno, $100 \mathrm{~m}$ de comprimento e $0,2 \mu \mathrm{m}$ de filme).

Dados Cinéticos: A cinética da fermentação alcoólica foi analisada pelo fator de conversão do substrato em produto ( $\mathrm{Y}_{\mathrm{P} / \mathrm{S}}$ ) pelo rendimento $(\mathrm{R})$. Estes foram calculados respectivamente de acordo com as Equações 1 e 2 (Borzani et al., 1975).

$$
\begin{aligned}
& Y_{P / S}=\frac{\Delta P}{\Delta S}=\frac{P_{f}-P_{i}}{S_{i}-S_{f}} \\
& R=\frac{\left(Y_{P / S}\right)_{\text {calculado }}}{\left(Y_{P / S}\right)_{\text {teórico }}} \times 100
\end{aligned}
$$

$\mathrm{O}$ termo $\mathrm{P}_{\mathrm{f}}$ é a concentração final do produto, neste caso, etanol. $\mathrm{O}$ termo $\mathrm{P}_{\mathrm{i}}$, correspondente à concentração inicial de produto (etanol), que foi considerada zero. Os termos $S_{i}$ e $\mathrm{S}_{\mathrm{f}}$ correspondem a concentração inicial e final do substrato, sendo neste caso a glicose.

A massa específica do etanol utilizada para os cálculos foi de 789,3 g/l (Najafpour e Lim, 2002). O fator de conversão máximo teórico foi utilizado como 0,51 grama de etanol por grama de glicose consumida, de acordo com a estequiometria da reação.

\section{RESULTADOS E DISCUSSÃO}

\subsection{Análise do Crescimento Celular e do Consumo de Glicose}

O gráfico do crescimento celular e do consumo do substrato durante o processo fermentativo de 30 horas está disposto na Figura 1.

Neste gráfico, pode-se perceber que o microrganismo possui atividade, obtendo-se concentração celular final de 7,37 g/l, e podendo-se considerar o consumo total do substrato (glicose). Observa-se ainda que no período entre 10 e 12 horas de fermentação, a concentração de glicose decai drasticamente, que é quando a levedura apresenta maior taxa de crescimento. Apesar da ausência de glicose, o microrganismo continua a crescer em função dos outros nutrientes.

Em termos de produtividade, percebe-se que o cultivo pode ser finalizado antes de 30 horas. Porém, como a análise das amostras só foi realizada no final do cultivo, permaneceu-se com o tempo de 30 horas previamente estipulado na metodologia. 


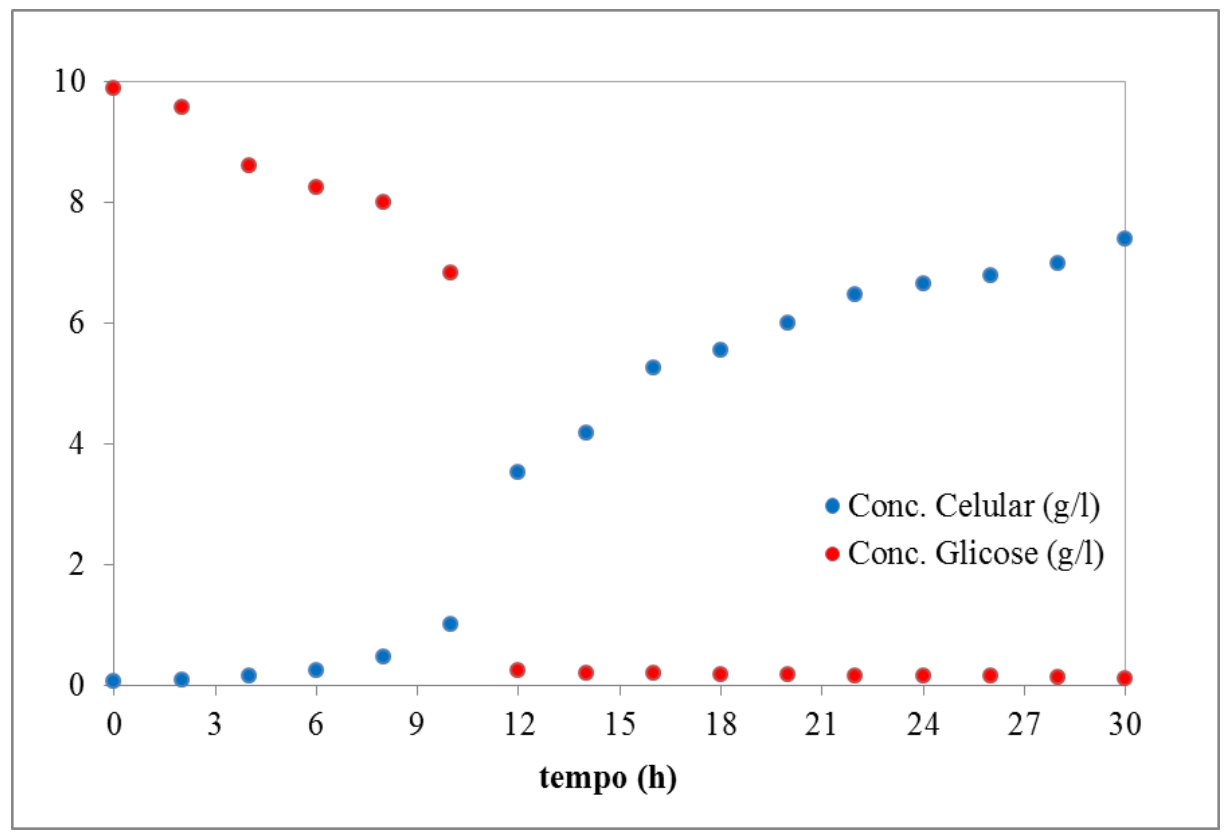

Figura 1 - Curva de crescimento da levedura CCT-3174 e do consumo da glicose.

\subsection{Análise Cinética}

A análise da cinética foi realizada considerando o fator de conversão de substrato em produto ( $\mathrm{Y}_{\mathrm{P} / \mathrm{S}}$ ) e o rendimento $(\mathrm{R})$. Para o substrato, considerou-se apenas a glicose. A concentração de etanol no final da fermentação alcoólica resultou em 4,846 g/l. As concentrações inicial e final de glicose resultaram em 9,88 g/l e 0,114 g/l respectivamente. Aplicando estes valores na Equação 1 obtém-se o valor de $\mathrm{Y}_{\mathrm{P} / \mathrm{S}}$, sendo este 0,496. E substituindo este $\mathrm{Y}_{\mathrm{P} / \mathrm{S} \text { calculado }}$ na Equação 2, obtém-se o rendimento, que resultou em 97,3\%.

No trabalho apresentado na literatura por Najafpour et al. (2004), a concentração inicial de glicose era de $50 \mathrm{~g} / \mathrm{l}$, e a fermentação alcoólica foi conduzida durante 27 horas com o microrganismo Saccharomyces cerevisiae ATCC 24860. O fator de conversão de substrato em produto obtido foi de $0,32 \mathrm{~g}_{\text {etanol }} / \mathrm{g}_{\text {glicose }}$.

De acordo com o trabalho desenvolvido por Mariam et al. (2009) o rendimento obtido na fermentação alcoólica foi de $0,75 \%$. Os autores avaliaram o processo conduzido pela levedura Saccharomyces cerevisiae GC-IIB3, sendo utilizado como meio o melaço da cana de açúcar com $15 \%$ de açúcares. Rodrigues et al. (2010) realizaram a fermentação alcoólica em suco de caju, com concentração de glicose em torno de $24 \mathrm{~g} / \mathrm{l}$, com a levedura comercial e em condições de operação de fermentação semelhantes às deste estudo. $\mathrm{O}$ maior fator de conversão obtido foi de 0,4 grama de etanol por grama de glicose consumida.

A discussão dos resultados obtidos neste estudo foi realizada com base em trabalhos publicados na literatura, porém, não foram encontrados trabalhos utilizando o mesmo meio de 
cultivo, nem fermentações alcoólicas utilizando a levedura Saccharomyces cerevisiae CCT-3174. A avaliação da capacidade fermentativa da levedura selecionada para este estudo foi realizada a partir de estudos que relatavam experimentos com outros meios e outros microrganismos.

\section{CONCLUSÕES}

Com os resultados obtidos neste estudo, é possível concluir que a levedura Saccharomyces cerevisiae CCT-3174 possui capacidade fermentativa. Com isto, esta levedura é passível de estudos futuro na obtenção de bioetanol, apresentando-se como possível alternativa à levedura comercialmente utilizada. Para estudos futuros, sugere-se o acompanhamento da concentração de etanol durante a fermentação alcoólica, para determinação do tempo necessário de fermentação com o intuito de se obter a máxima produtividade do processo.

\section{REFERÊNCIAS}

BORZANI, W.; LIMA, U. de A.; AQUARONE, E. Engenharia Bioquímica. São Paulo: Edgard Blücher, 300p, il. Biotecnologia, v. 3, 1975.

BORZANI, W.; LIMA, U. A.; AQUARONE, E.; SCHMIDELL, W. Biotecnologia Industrial. São Paulo: E. Blücher, v. 3, 2001.

DODIC, S.; POPOV, S.; DODIC, J.; RANKOVIC, J.; ZAVARGO, Z.; JEVTIC, M. Bioethanol production from thick juice as intermediate of sugar beet processing. Biomass Bioenergy, v. 33, p. 822-827, 2009.

HAHN-HAGERDAL, B. Bio-ethanol - the fuel of tomorrow from the residues of today. Trends in Biotechnol, v. 24, n. 12, 2006.

MARIAM, I.; MANZOOR, K.; ALI, S.; HAQ, I. U. Enhanced production of ethanol from free and immobilized Saccharomyces cerevisiae under stationary culture. Pak J Bot, v. 41(2), p. 821-833, 2009.

MOHANTY, S. K.; BEHERA, S.; SWAIN, M. R.; RAY, R.C. Bioethanol production from mahula (Madhuca latifolia L.) flowers by solid-state fermentation. Appl Energy, v. 86, p. 640-644, 2009.

NAJAFPOUR, G. D.; LIM, J. K. Evaluation and Isolation of Ethanol Producer Strain SMP-6. Reg Symp Chem Eng, Malásia, p. 229-236, 2002.

NAJAFPOUR, G.; YOUNESI H.; ISMAIL K. S. K. Ethanol fermentation in an immobilized cell reactor using Saccharomyces cerevisiae. Bioresour Technol, v. 92, p. 251-260, 2004.

ORTIZ, S. Produção de Bioetanol a partir de Resíduos Agroindustriais. Dissertação de Mestrado, Programa de Pós-graduação em Engenharia Química, Universidade Regional de Blumenau - FURB, Blumenau - SC, 2010.

RODRIGUES, T. H. S.; PINHEIRO, A. D. T.; REGO, D. R. B.; ROCHA, M. V. P.; MACEDO, G. R. de; GONÇALVES, L. B. Avaliação do potencial do pedúnculo de caju (Anacardium 
occidentale L.) para a produção de bioetanol por Saccharomyces cerevisiae. XVIII Congresso Brasileiro de Engenharia Química, Foz do Iguaçu - PR, Brasil, 2010.

VIEIRA, G. E. G.; PICKLER, A.; CASTRO, J. G. D; CARDOSO, A. S.; FIGUEIREDO, R. L.; SILVEIRA, A. S.; MILHOMEM, C. C.; LEAL, E. R. M.; PEDROZA, M. M.; MAFRA, W. A.; SILVA, F. C.; LIMA, M. M.; CARVALHO, M. B.; BOAS, V. F. V. Obtenção de etanol a partir do mesocarpo de babaçu (Orbignya sp.). $2^{o}$ Simpósio Nacional de Biocombustíveis, 2009. Disponível em: http://www.abq.org.br/biocom/2009/trabalhos/-115572.htm. Último acesso em: 23/03/2014.

XIROS, C.; TOPAKAS, E.; KATAPODIS, P. CHRISTAKOPOULOS, P. Hydrolysis and fermentation of brewer's spent grain by Neurospora crassa. Bioresour Technol, v. 99, p. 5427-5435, 2008. 